\title{
The Complexities of Employee and Institutional Interactions for Human Capital Development: Evidence from Banking Network of Ghana
}

\author{
Alex Boadi Dankyi1*, Yusheng Kong1, Philip Agyei Peprah1, \\ Asabea Addo Antoinette ${ }^{2}$, Evans Takyi Ankomah-Asare ${ }^{3}$ \\ ${ }^{1}$ School of Economics and Finance, Jiangsu University, Zhenjiang, China \\ ${ }^{2}$ School of Management, Jiangsu University, Zhenjiang, China \\ ${ }^{3}$ National Council for Tertiary Education, Accra, Ghana \\ Email: *alexboadidankyi@stmail.ujs.edu.cn,yshkong@ujs.edu.cn, asabeaaddo@ujs.edu.cn, acubefebruary@gmail.com, \\ e.takyi@ncte.edu.gh, e.takyi@ujs.edu.cn
}

How to cite this paper: Dankyi, A.B., Kong, Y.S., Peprah, P.A., Antoinette, A.A. and Ankomah-Asare, E.T. (2020) The Complexities of Employee and Institutional Interactions for Human Capital Development: Evidence from Banking Network of Ghana. Open Access Library Journal, 7: e6237.

https://doi.org/10.4236/oalib.1106237

Received: March 16, 2020

Accepted: April 17, 2020

Published: April 20, 2020

Copyright $\odot 2020$ by author(s) and Open Access Library Inc.

This work is licensed under the Creative Commons Attribution International License (CC BY 4.0).

http://creativecommons.org/licenses/by/4.0/

\section{(c) (i) Open Access}

\begin{abstract}
The paper focused on the human capital development capacity of complex interactive institutional networks. Network principles were adopted to seek the underlying conditions that determine the human capital development of institutions as well as its capacity to sustain personnel development within competitively dense networks. The research focused on existing management structures hinged on the assumption that it influenced policy development, implementation, and worker engagements intending to increase institutional performance within the competitive space. Using some core attributes, a network was developed to capture the interaction between employees within an institution as well as their comparative impact on the general banking system of a developing economy. Using specific network measures, we deduced the institutional network was efficient in human capital development, and also efficiency in competitive networks is inversely proportional to density. Multi-national Banks have higher potentials of human capital development in a highly competitive industry compared to indigenous banks. Again connectivity dynamics affect human capital development in financial networks in developing countries.
\end{abstract}

\section{Subject Areas}

Human Resource Management

\section{Keywords}

Organizational Learning, Human Capital, Social Network Analysis, Institutional 
Networks, Management Team

\section{Introduction}

The conceptual background of Human Capital (HC) recognizes that employees do not present the same set of knowledge and skills at a workplace and that the quality of employees' skills set and knowledge base is directly related to the investment made on the employee and can be improved by investing in the employee's education, experience and abilities within the workspace. Alic [1] believes that current trends suggest that the institutional assessment of $\mathrm{HC}$ is more focused on the policies that recruit, retain, and enhance the initial skill set of the workforce. Thus, to minimize cost, institutions have resorted to recruiting highly skilled labor and harnessing their competencies to activate on the job training for less-skilled personnel. Business ecosystems have their foundations deeply rooted in the complexity of technology linked innovation as well as specialization. This fuels individual enterprises' quest for a strong, competitive and efficient human capital infused with the requisite knowledge and skills-set that assures institutional performance and growth [2] [3]. It is therefore not surprising that organizations are keen on the human capital capacity and potential growth before worker engagement.

The Resource-Based View (RBV) of strategic management posits that analyzing the human resource of a specific firm in terms of its potential to serve as a source of sustainable competitive advantage requires an examination of, among others, the resource value [4] [5] [6] [7] [8].

Most studies on the human capital capacity of firms especially within finance systems are usually hinged on statistical approaches that rely on averaging of scores and its subsequent inferences and deduction which is defective of unaccounted for variations.

Network analysis is a fundamental approach to the study of social structure and seeks to address social loopholes that are not accounted for in an attempt to study socially interacting variables [9] [10] [11]. Network Analysis can be used to help explain social relations and the resulting impact on desired outcomes, by factoring in the levels as well as the intensity of interaction and individual attributes of the actors all within a considerable time of interest [12] [13] [14].

The literature illustrates the growing recognition of the potential value of using network theories to examine how structure and nature of interaction in networks might influence the development of human capital and its spread within and outside the network as a result of the ensuing interactions [15]. Increased interest in human capital development and collaborative networks has yielded techniques and mathematical models that hope to assist in the numerical and visual analysis of the evidence of network developments and evolutions. The underlying logic is that human capital development within a particular domain 
depends on the quality and quantity of both formal and informal relationships among actors within the network [16].

In this study, we adopted a network approach to visualize and analyze the human capital development capacity of the financial network in a developing country and ascertain its efficiency in human capital development.

\section{Social Network Theory and Analysis}

Graph theory has gained recognition in research in more recent years. Graph theory in human studies often presents vertex covering problems which are classified under determinacy environmental problems in which all the edges and vertices can be completely determined [17]. One area of classical graph theory application is in social networks [18] [19].

Yousefi Nooraie, EM Sale [20] explains that a social network is a social structure made of actors, which are connected. The strength or intensity of this connection is a measure of the type and or characteristics of the relationship between the actors by one or more. Its representation can be made through a graph where the vertices represent individuals or entities and the edges, the relations among them [21]. Formally a simple social network is modelled as a graph $G=(V, E)$ where, $V=\left(V_{1}, V_{n}\right)$ is the set of vertices or nodes, represented as entities or individuals. $E$ is the set of social relationships, represented as edges in the graph, where $E=\left(V_{i}, V_{j}\right) \mid V_{i}$ and $V_{j} \in V$ [9] [22] [23] [24] [25] [26], which hinges on the Reductionism Theory; as stated by Barabási, Ravasz [12].

Norbutas and Corten [27] posit that social networks adopt specific indicators to analyze measures such as cohesiveness, centralities, and prestige. Cohesion measures of the network are considered by researchers as an index of the systematic connectedness of any interactive space. Some indicators of analysis under this general component are degree, centralization, density, closure, distance, diameter, dependency sum, mutual, breadth, etc.

This research shall use indicators such as Efficiency, Density, Average distance, Clustering coefficients, Degree centrality, Eigenvector centrality, Information centrality and betweenness in its analysis of the human capital development interactions within the financial network.

\subsection{Efficiency}

This measures how efficient exchanges of information take place within a network. Thus, efficiency quantifies the exchange of information across the whole network where information is concurrently exchanged. The paper employs Latora and Marchiori [28] model of average efficiency and expressed as:

$$
E(G)=\frac{1}{n(n-1)} \sum_{i \neq j \in G} \frac{1}{d(i, j)}
$$

where $n$ denotes the total nodes in the network

$d(i, j)$ denotes the length of the shortest path between a node $i$ and another node $j$. 


\subsection{Density}

This measure is considered as the number of connections divided by the number of possible connections. A completely linked network has a density of 1 . It is calculated by first determining the potential connections $(p c)$ a network can have, expressed as

$$
p c=\frac{n *(n-1)}{2}
$$

$n=$ number of actors in the network;

Density is therefore deduced as $\frac{\text { actual connections }}{\text { potential connection }}$.

\subsection{Average Distance}

The average distance in a network is the average length of all shortest paths between all pairs of connected actors in the network. Since our research employed an undirected connection between actors, the formula we will use in calculating the average distance within our financial network adopts a model presented by [29].

$$
\bar{d}=\frac{\sum_{u \neq v}\{d(u, v), \forall u, v \in V\}}{n(n-1)}
$$

where,

$$
\begin{aligned}
& d=\text { distance between two actors; } \\
& u, v=\text { actors with a connection within a given network; } \\
& n=\text { number of actors within a network within which } u, v \text { are actors. }
\end{aligned}
$$

\subsection{Clustering Coefficient}

Chahin, Hoffmeister [30] opines that coefficient reflects the degree to which the nodes tend to organize together and characterizes the transitivity of interactions within the financial network. Specifically, the clustering coefficient of a node quantifies how close the node and its neighboring actors are, to being a complete subgraph (Barnes et al., 2016). In this paper, it is calculated as:

$$
C_{i}=\frac{2 \mid\left\{e_{j k}: v_{k} \in N_{i}, e_{j k} \in E\right\}}{K\left(k_{i}-1\right)}
$$

Let $k_{i}$ be the number of vertices, $\mid N_{i}$, in the neighborhood, $N_{i}$, of a node, $i$ and $E$ is the Network.

The network average clustering was calculated using the approach suggested by [31] [32].

$$
\bar{c}=\frac{1}{n} \sum_{i=1}^{n} C_{i}
$$

\subsection{Degree Centrality}

This measure takes into consideration the quantitative measurement of actors' 
connections within a network. It usually accounts for active and dormant actors within a network. The Network Degree Centrality was calculated using the Freeman formula [33] [34] [35] [36].

$$
G D C=\frac{\sum\left(\max D C^{\prime}-D C^{\prime}\right)}{(N-1) *(N-2) /(2 * N-1)}
$$

where $N$ is the number of actors within the network and $D C^{\prime}$ is the normalized degree centrality.

\subsection{Eigenvector Centrality (EVC)}

The eigenvector measures the relative influence or importance of an actor in a particular network. It premises that a high index value indicates that an actor is connected to important and more influential actors [37] [38] [39]. In calculating, we assumed that for a given graph $A=(V, E)$ with $|V|$ vertices, let $A=h_{v, r}$ be its adjacency matrix such that $h_{v, t}=1$ if $v$ is linked to $r$, and 0 if otherwise. Thus, the eigenvector centrality of actor $v$ was defined as

$$
y_{v}=\frac{1}{\omega} \sum_{r \in M(v)} y_{r}=\frac{1}{\omega} \sum_{r \in A} h_{v, r} y_{r}
$$

Such that $M(v)$ is a set of neighbors of $v$ and $\omega$ is a constant. This can subsequently be written as $A x=\omega x$.

\subsection{Information Centrality}

The information centrality measure of a network is an average of the information of all paths from a particular actor. In an incidence of two or more connections between a pair of nodes or actors containing some of the same incident nodes in a network, the information centrality is calculated using a matrix containing the number of incident nodes that share the connections and vice versa. The average centrality of information for a given graph is expressed as

$$
\overline{I F C_{i}}=\overline{I_{i}}=\frac{n}{\sum_{j=1}^{n}\left(\frac{1}{I_{i j}}\right)}
$$

where $n$ is the number of nodes and $I_{i j}$ the centrality of a path from node $i$ to $j$. Alternatively, it can be calculated using the symmetrized socio-matrix of $N \times$ $N($ e.g. $A)$ such that $A_{i i}=1+d_{i}$.

Conditionally $A_{i j}=1$, if $(i, j)=0$. Then $A_{i j}=w_{i j}$ if $(i, j)=w_{i j}$. Next, compute the inverse matrix of $A$, for instance, $D$ using the $L U$ decomposition approach (Barnes et al., 2016). This allows for the information centrality of a node to be computed by

$$
I F C_{i}=I_{i}=\frac{I C_{i}-1}{D_{j i}+\frac{T-2 R}{N}}
$$

where $T$ is the trace of matrix $D$ (the sum of diagonal elements) and $R$ is the sum 
of elements of any row (since all rows of $D$ have the same sum). Note that in this case, information centrality has a minimum value, but no maximum.

\subsection{Betweenness Centrality}

Is defined as the share of times that a node $i$ needs a node $k$ (whose centrality is being measured) to reach a node $j$ via the shortest path [40]. Specifically, if $g_{j i}$ is the number of geodesic paths from $i$ to $j$ and $g_{i k j}$ is the number of these geodesics that pass through node $k$, then the betweenness centrality of node $k$ is given by

$$
\sum_{i} \sum_{j} \frac{g_{i k j}}{g_{i j}}, i \neq j \neq k
$$

\section{Conceptual Frame}

From Figure 1, the input level comprises individual employees with a set of skills and knowledge ideas (human capital) in a particular banking entity. The study holds that the individual employees are embedded with multi-attributes of human capital which determined individual human capital index. Generically these indexes involve Academic qualifications (A) Post-secondary Schools attended (S), Professional Association they join (P), the Human Capital Index of Countries worked or schooled in for a year or more (C), and their aggregated years of work experience (E). The underpinning logic for assessing organization human capital index as an accumulation of the indexes of its members stems from the argument that the aggregation of members' knowledge and skillsets in a particular institution forms its inventory of Human capital [7]. The complexity of discussions bothering highly interactive but competitive spaces like banking

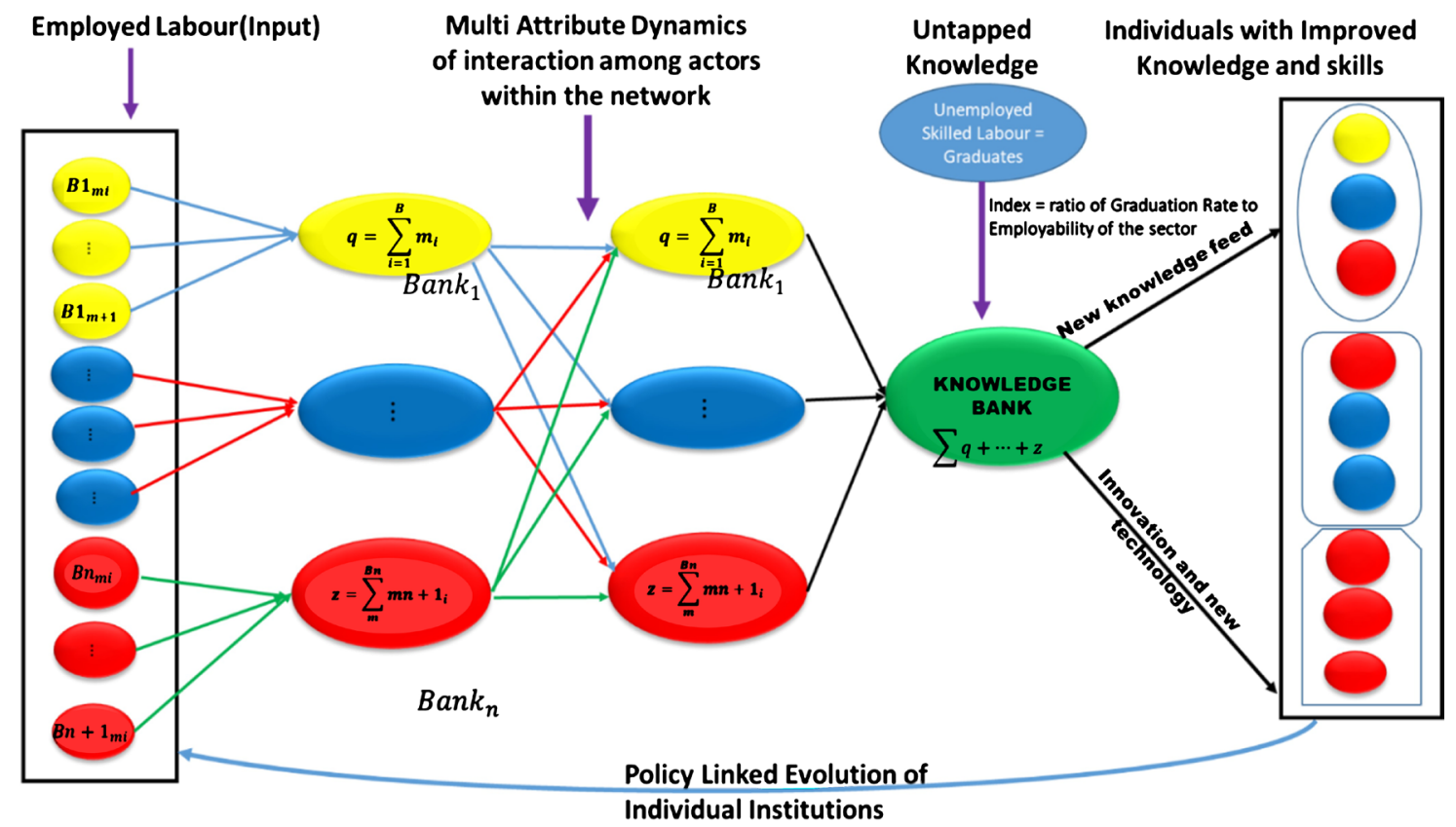

Figure 1. The network dimensions of human capital development. 
and finance follows the analogy that, the individual employees (Actors) at the individual Banks interact with employees not only in their Bank but other actors within the financial network by their association through several common attributes, for example, professional associations, training camps and or non-bank related social network relations.

The framework posits that there are hidden layers of the transformation of the skill set and knowledge that individual employees present, acquire, diffuse and adopt to colleagues and inadvertently competitor's employees through training and development programs that are undertaken by each institution as they seek a competitive advantage. This transformational knowledge stage is experienced uniquely but jointly by banks within a competitive network. This is more so in networks hosted within emerging economies with structural limits and dynamic regulations. This is because each Bank develops unique policies and resources aimed at creating competitively advantageous niches within an emerging economy, especially where customer bases are quite limited. The developed policies and programs targeted human capital development by such institutions are inherently complex and dynamically responsive to changes within the system. This accounts for differences among Actors of different banks who share common or similar attributes.

Further, from the framework (Figure 1), the multi-attribute dynamics of the complex interaction between actors coupled with the hidden layers of knowledge transformation accounts for the total knowledge pool within the system per any given period. Because the system within which the competitive network operates seeks competitive advantage through the churn out of new employable individuals from its formal and informal skills training outlets provide the banks with new untapped but potential human capital. The untapped potential human capital index is a reflection of the ratio of graduation rate to the employability rate in the industry.

The presence of competition, personal and institutional drives of actors to improve their social status and influence acts as a catalyst for the acquisition and diffusion of knowledge and skill set. Attrition and fragmentation are a result of unfavorable and challenging systemic policies that either affects banks or employees based on their ability to conform to new and existing policies at any point in time. Decisions made, therefore, are integrally dependent on the interpretation of such policies and practices. For individual employees, this becomes the enclave of HR policies and practices at the Individual banks. The long term effect is an ever-changing cycle of knowledge generation and innovation that drives the system. This deepens the complexity of the relationship that exists between actors and institutional networks. The whole relationship, then, is injected with an ability to adapt, generate and diffuse knowledge innovations through the dyadic relations between and among actors in the network.

The individual Banks as actors in the network equally evolve policy-wise to reflect the human capital dynamics at play per any given period. This emanates 
from the quest of this individual Banks to gain a competitive advantage in the competitive financial space. The Knowledge pool, therefore, impacts on policies such as recruitment that includes poaching highly skilled and knowledgeable personnel and organizing training and development programs to meet the state of art practices and operations for sustainable growth. Resource persons for training are eventually sourced through existing professional network paths as specializations emerge. It is noteworthy that social networks are perpetual processes of complex systems that factors in history and this allows the relationship to evolve and grow in dynamism and complexity.

\subsection{Research Questions Development}

In developing countries, the cost of acquisition of set-of-work skills is strongly dependant on national subventions supported by family linked stipends. Research suggests that national subventions are used to provide formal and in the rare instance, informal skills acquisition of citizens. Post education skills development is considered to be the domain of the employer. The underpinning reason being that skill sets owned after education is designed to occupy specific job-related niches. Thus job-related skill training falls within the major domain of employers since they are the direct beneficiaries [1] [5] [7]. Researchers have argued that cultural diversity within and amongst workers in institutional networks; with high centrality measures have the opportunity to harness information flow through the various connections within the network. Such individuals also are critical in imparting information on other actors within the network. Highly centralized individuals' human capital in networks is therefore essential for the nurturing and development of new entrants within the network. The study posits that financial institutions which have more of their workers in highly centralized positions in a complex interactive network involving other financial institutions are competitively advantageous; [2] [41] Further deducing from the competitive advantage angle, question one is hypothesize such that:

1) Do multi-national banks have a stronger impact on human capital development of the financial sector network in emerging economies?

There is a widespread belief in the literature that Human Capital is contingent on interactions and interdependencies between actors in a network and is directly influenced by the quality of these interactions. This is very relevant in assessing capacity building within networks [2] [32] [40]. We, therefore, write research question two as:

2) Do the connection dynamics of actors in a financial network influence human capital development in emerging economies?

Management team members are embedded in financial networks of cooperative relationships that influence the flow of resources among them. Dynamic resource flows and differentiated structural positions lead to one's influence in the network [38] [41] [42]; Based on the aforementioned, research question three is hypothesized such that: 
3) Do management team members' positions held in a financial network influence their role in human capital development in emerging economies?

\subsection{Network Development}

The banking network of Ghana is made up of six listed banks with varying stock performance on the Ghana Stock Exchange. The study focused on management team members of individual banks due to their strategic role in human capital development and general bank performance. Bantel [43] used information from the curriculum vitae of management team members, data on the attributes such as academic qualifications, educational institutions attended, experience, and the professional association was collected for individual members within each institution. Actors were considered connected if and when they shared a common attribute. In such situations, their connection weight was the sum of their common attributes coefficient or value. All connections were not directed.

Figure 2 indicates network association per variables selected for the study.

\subsection{Attribute value determination}

The study adopted attribute value determination in our earlier paper [44].

\subsubsection{Academic Qualification}

The essence of academic qualification impacting on Human Capital has been put forward by many scholars. In the current complex and incongruous professional worlds, where there is no blueprint for dealing with unpredictable people and events, individuals must develop reflexive approaches to professional identity building, disciplinary knowledge and skills, and higher education because these variables have a crucial role to play in guiding workers to examine and mediate self concerning context for effective decision-making and action [45] [46] [47] [48]. It was detected from the data that the minimum academic qualification was a bachelor's degree and the highest was a Ph.D. Since these academic qualifications are hierarchically ranked Bachelor's Degree, Master's Degree and Ph.D., raw scores from 1 to 3 were assigned to them. In a situation where individuals had more than 1 academic qualification, the sum of the individual qualifications was considered as the total academic score of the person.

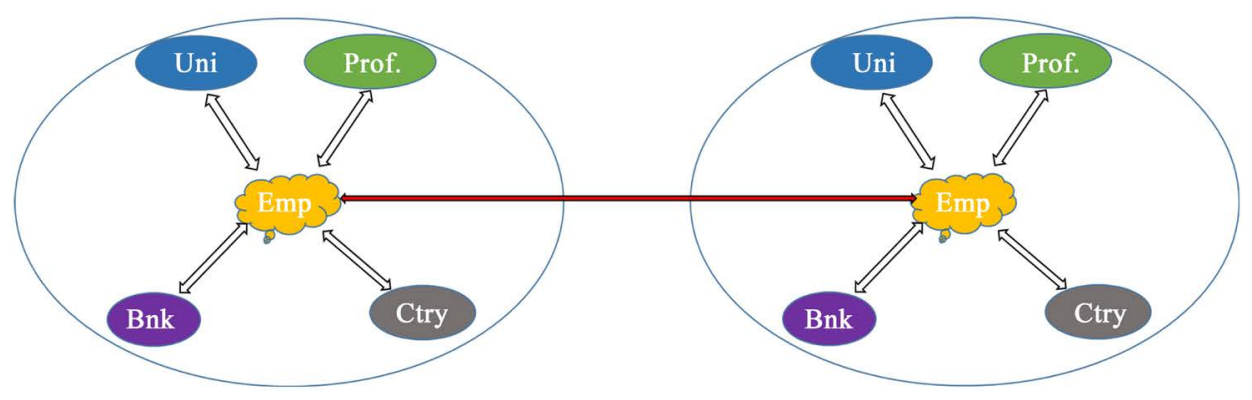

Universities = Uni, Professional Association $=$ Prof. Countries of association $=$ Ctry, Current Bank $=$ Bnk . And Employee/Actors $=$ Emp.

Figure 2. Network relations. 


$$
A=\sum_{i=1,2,3} a_{i}
$$

where,

$a=$ Corresponding academic qualification score;

$A=$ Total Score obtained on individual academic qualifications;

$i=$ Individual scores of the academic equation.

\subsubsection{Educational Institutions Attended}

In the scoring of schools (universities), the Times Higher Education Ranking was used. The schools were carefully selected according to their ranks and arranged in descending order. The schools were then inversely scored after attaining their ranks on the 2018 league table in descending order. The times higher education was adopted because it is a global university performance table that judge research-intensive universities across all of their core missions: teaching, research, knowledge transfer and international outlook. The ranking uses 13 carefully calibrated performance indicators to provide the most comprehensive and balanced comparisons, trusted by students, academicians, university leaders, industry and governments. The calculation of the rankings for 2018 has been subject to independent audit by professional services firm PricewaterhouseCoopers (PwC) (Times Higher Education, 2018). This is expressed as:

$$
S=S_{i j}=\sum_{i=1}^{n} \sum_{j=1}^{n} U_{i j}
$$

Decomposing (1), gives:

$$
\sum_{y=1}^{n} S_{j i}=\sum_{i=1} U_{i}
$$

Where (12) and (13) are conditionally premised on

$$
\left.\begin{array}{c}
S_{i 1}=U_{i 1}+U_{i 2}+\cdots+U_{i n} \\
\vdots \\
S_{N i}=U_{N 1}+U_{N 2}+\cdots+U_{N n}
\end{array}\right\} \text { premise 1 }
$$

where,

$S_{i 1}=$ Total universities an individual has attended;

$U_{\text {in }}=$ Individual score of a University;

$i \& j=$ Universities.

\subsubsection{Countries}

On the part of Countries, the study adopted the 2017 Global Human Capital Index which provides a quantifiable way to measure the human capital of a country based on citizens' ability to acquire, develop, and use new skills beyond their years of schooling and during their professional lives. Countries that management team members had interacted with for a year or more are believed to influence their experiences acquired [48] [49] opines that one's physical environ- 
ment of work or training has a major impact on knowledge acquisition and deployment. The ranks of the countries that management team members have interacted with for at least a year (worked and schooled in) were extracted and inversely scored.

$$
B=B_{i j}=\sum_{i=1}^{n} \sum_{j=1}^{n} X_{i j}
$$

Decomposing (1), gives:

$$
\sum_{y=1}^{n} B_{j i}=\sum_{i=1} X_{i}
$$

where, (14) and (15) are conditionally premised on

$$
\left.\begin{array}{c}
B_{i 1}=X_{i 1}+X_{i 2}+\cdots+X_{i n} \\
\vdots \\
B_{N i}=X_{N 1}+X_{N 2}+\cdots+X_{N n}
\end{array}\right\} \text { premise 1 }
$$

where

$B_{i 1}=$ Total countries an individual has visited;

$X_{\text {in }}=$ Individual score of a country;

$i \& j=$ Countries.

\subsubsection{Experience}

Working experience which is the number of years that a management member has been working was adopted in its raw form and used as the score. [50] [51] have availed empirical evidence to prove that working experience affects one's knowledge base which in turn affects the human capital capacity of firms. The work experience attributed coefficient of an actor within this study was derived as

$$
E=E(x)=n
$$

where,

$E=$ Total score of Experience;

$n=$ Number of years of experience.

\subsubsection{Professional Association}

A professional association is a key to human resource empowerment [52]-[60]. In this study, the authors reviewed the various professional associations that actors could potentially belong to. A point was allocated per association such that the total number of professional association points scored was commiserative of the total number of associations an actor listed membership of on his or her cv. This is aptly represented as. bership of on his or her cv. This is aptly represented as.

$$
P=\sum_{i=1} \sigma_{i}
$$


where,

$$
\begin{aligned}
& P=\text { Total score for a professional association; } \\
& \sigma=\text { Professional qualifications; } \\
& i=\text { Individual scores of professions. }
\end{aligned}
$$

The total score of an individual $(Z)$ on the variables of assessment as determined in (1), (3), (15), (6) and (17) is a simple summation expressed as

$$
Z_{v}=\sum_{v}^{n}(S+B+E+A+P)
$$

To find the proportional influence of individuals within the financial system, we first found the total possible score within the system and determined the individual's contribution as a percentage influence.

Thus, individual influence in system $=$ (individual score/total system score $) \times$ 100.

\subsection{Data Analysis}

The UCINET 6 for windows version 6.658 was used as the analytical tool for the network. The condition for interaction between actors in a network has always been contingent on proximity (closeness, distance), accessibility (centrality) and similarities (clusters). The argument is that all things being equal, proximity, accessibility, and similarities are catalysts for establishing relationships between actors within a network. The measures employed are Degree centrality: which counts the number of connections an individual has, Betweenness centrality: which reflects individuals positioned on the shortest paths connecting other individuals on the social network. Individuals have high eigenvector centrality if they have many connections and when these connections are relatively important as well. The clustering coefficient reflects how strongly connected the connections of an individual are, and is related to the macro-level transitivity measure.

Figure 3 represents a pictorial view of social network connections of the listed banks in Ghana with red nodes representing management positions, blue nodes representing professional bodies, green nodes representing universities in the world that management team members have interacted with for a year or more and yellow nodes representing countries actors have interacted with.

\section{Results}

\subsection{Network Efficiency}

Network efficiency was measured to ascertain the efficiency of the financial network in human capital development.

Figure 4 represents the network efficiency and Degree of Actors.

The network had an average degree connection of 8.01 with an average density of 0.566 at an efficiency of 0.598 . In Figure 4 , the circled area depicts the point at which density and efficiency were at equilibrium. The figure again generally showed an inverse relationship between efficiency and density, thus as the network became denser, the flow of knowledge or information required to de- 
velop human capital declined. This is typical of a financial network where competition within and amongst institutions vis-à-vis corporate governance structures restrict the share of human capital across institutions [5] [61] [62].

\subsection{Micro-Level Measures of the Financial Network}

Degree, Betweenness, Information, and Eigenvector centrality analysis of the financial network and results are presented in Figure 5. The normalized average Degree of the centrality of the general network is 0.043 . The normalized average Betweenness of the general network is 0.186 . Further the normalized average Eigenvector centrality of the general network is 0.115 . Finally, in Figure 5, the Information Centrality results indicate a normalized average of 0.256 . The slope of Degree Centrality and Betweenness is 0.055 and that of Eigen Vector Centrality and Information Centrality is 1.732 .

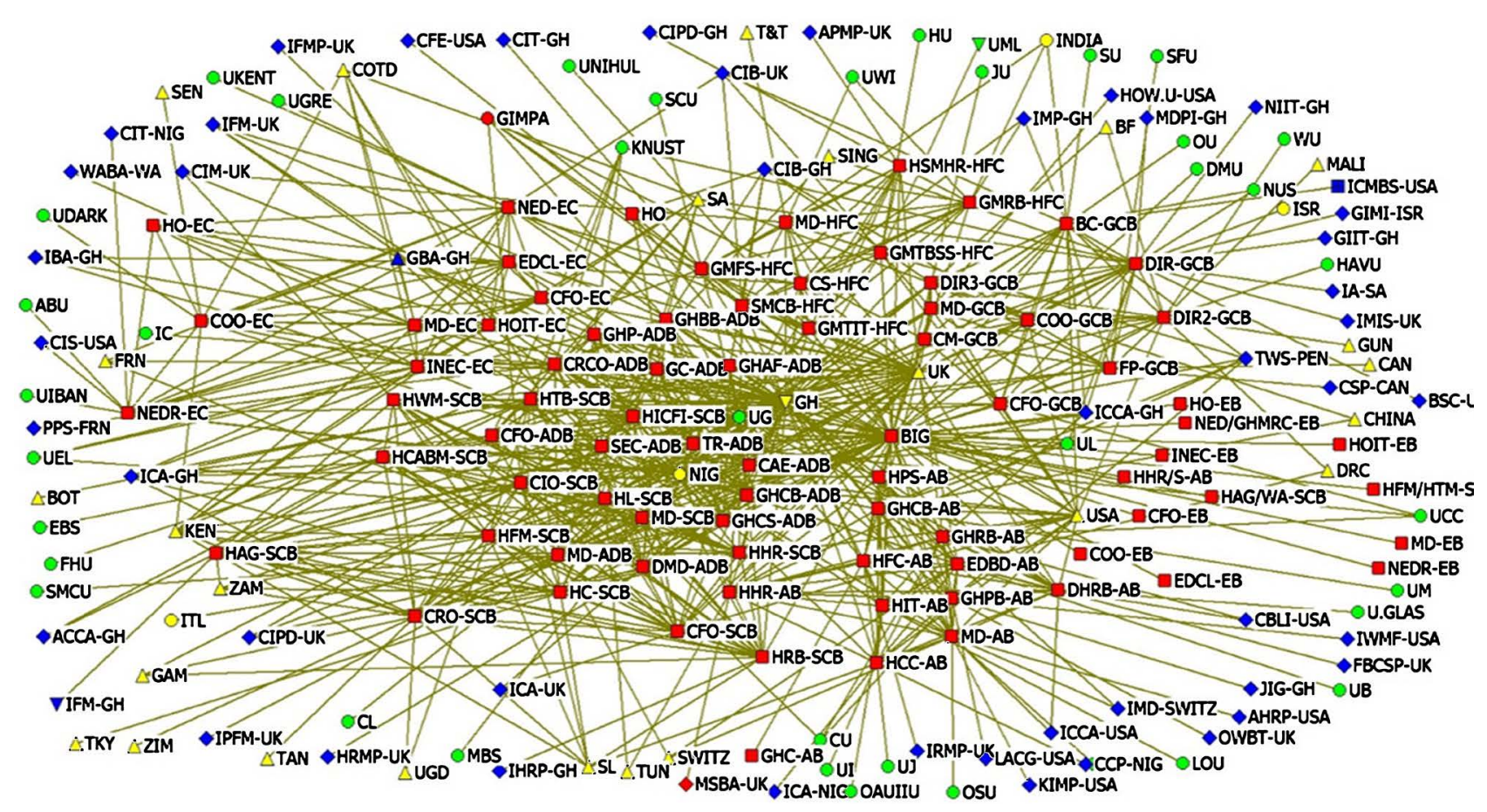

Figure 3. General financial network.

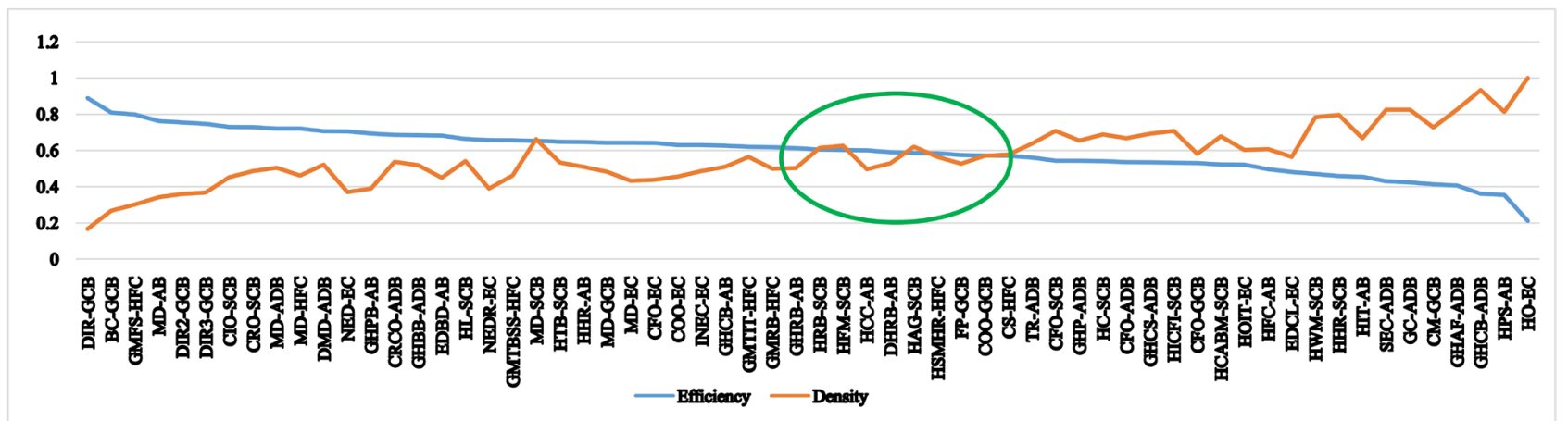

Figure 4. Efficiency and degree of actors. 
Figure 6 displays the scatter plot of the clustering coefficient of the financial network. The overall clustering co-efficient of the financial network was 0.976 and the Clustering techniques used grouped human capital development capability and relative importance of the actors in hierarchical levels. The average clustering value is used as a benchmark concerning the deviation in the determination of the levels. This gives a fair idea about individual and group influence based on cluster levels [63] (see Table A1 for individual clustering coefficient).

\subsection{Ego-Net Analysis}

The analysis of the ego-nets of the six banks is presented in Figures 7-12 below.

Figure 7 represents the Egonet of access Bank capturing its average degree centrality (0.263) and information centrality of 0.132 .

Figure 8 represents the Egonet of access Bank capturing its average degree centrality (0.422) and information centrality of 0.158 .

Figure 9 represents the Egonet of access Bank capturing its average degree centrality (0.323) and information centrality of 0.175 .

Figure 10 represents the Egonet of access Bank capturing its average degree centrality (0.206) and information centrality of 0.154 .

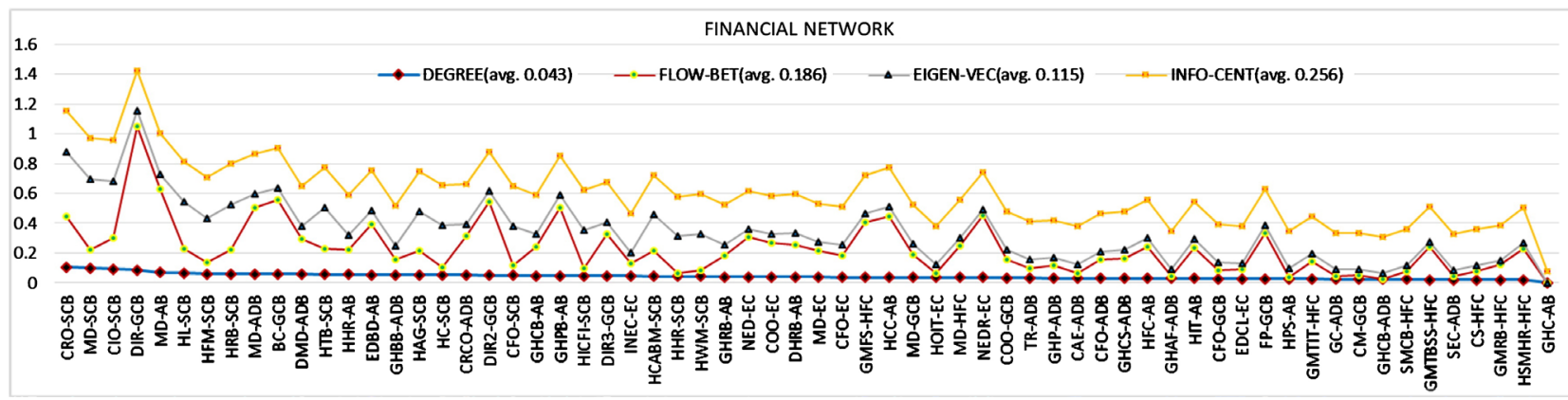

Figure 5. Micro-Level measure of the financial network.

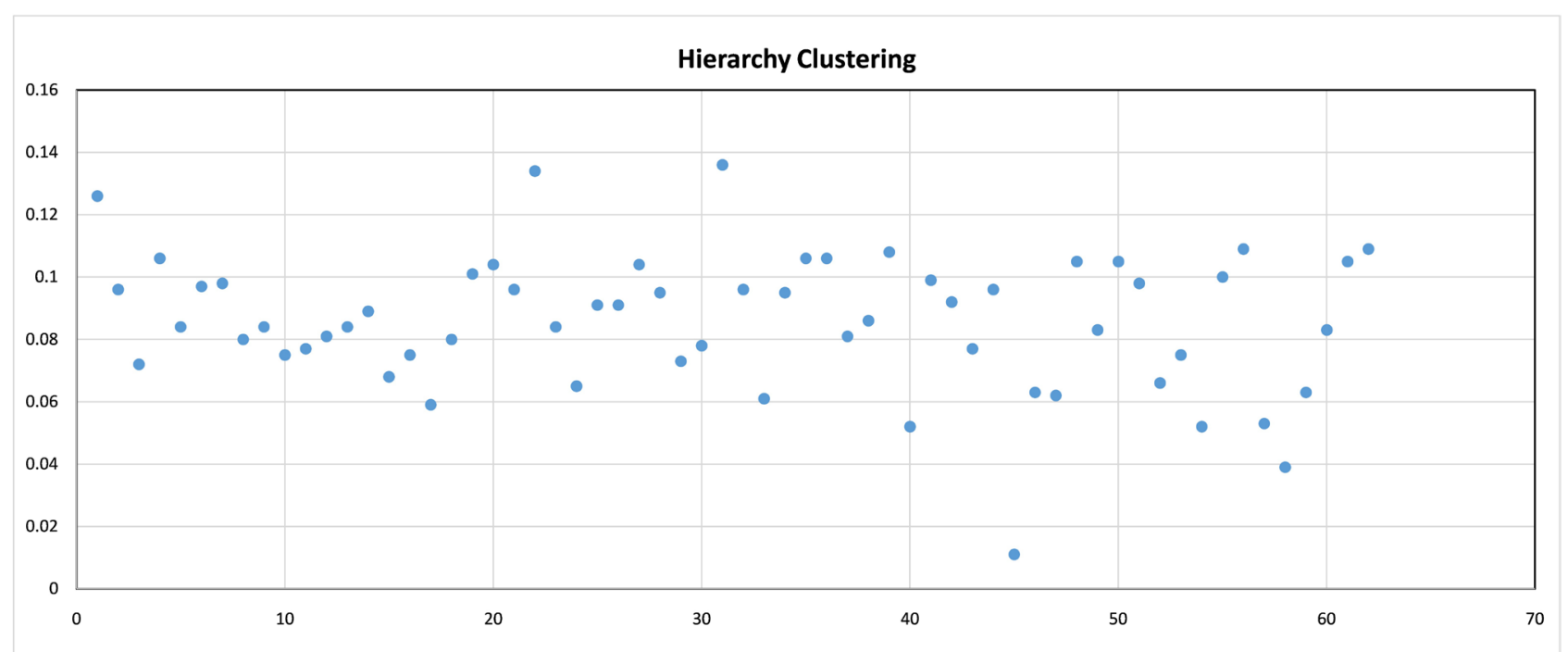

Figure 6. Hierarchical clustering of actors. 


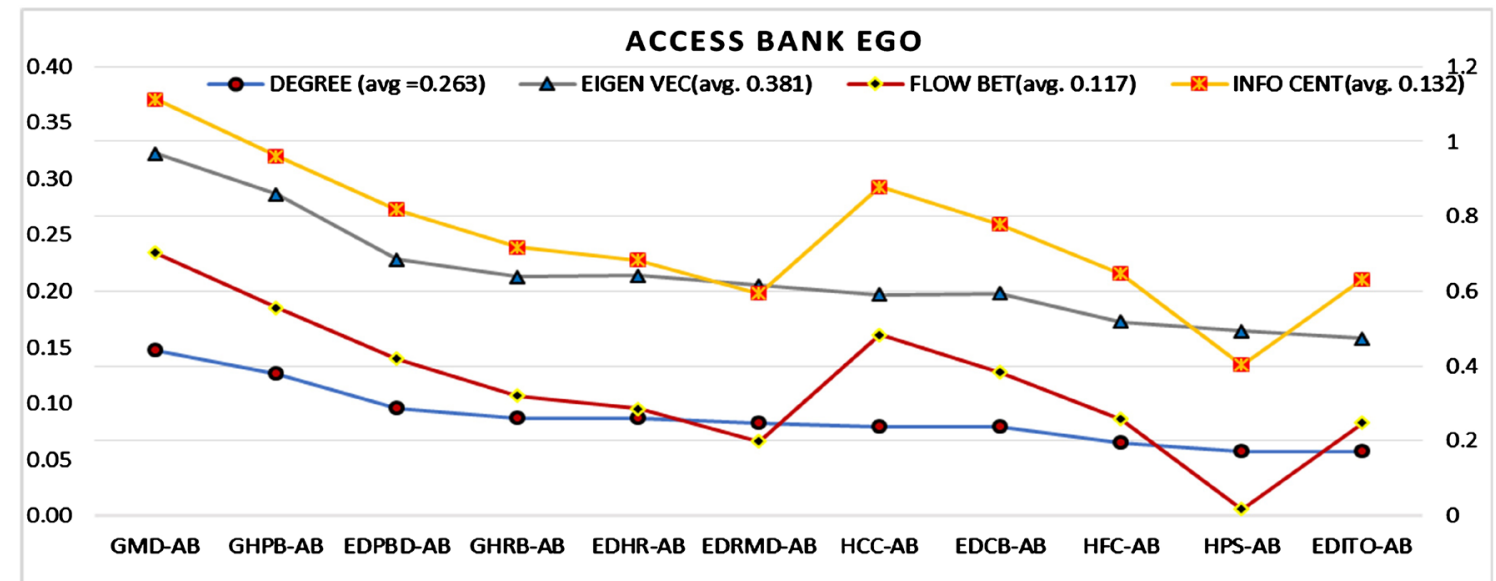

Figure 7. Access bank.

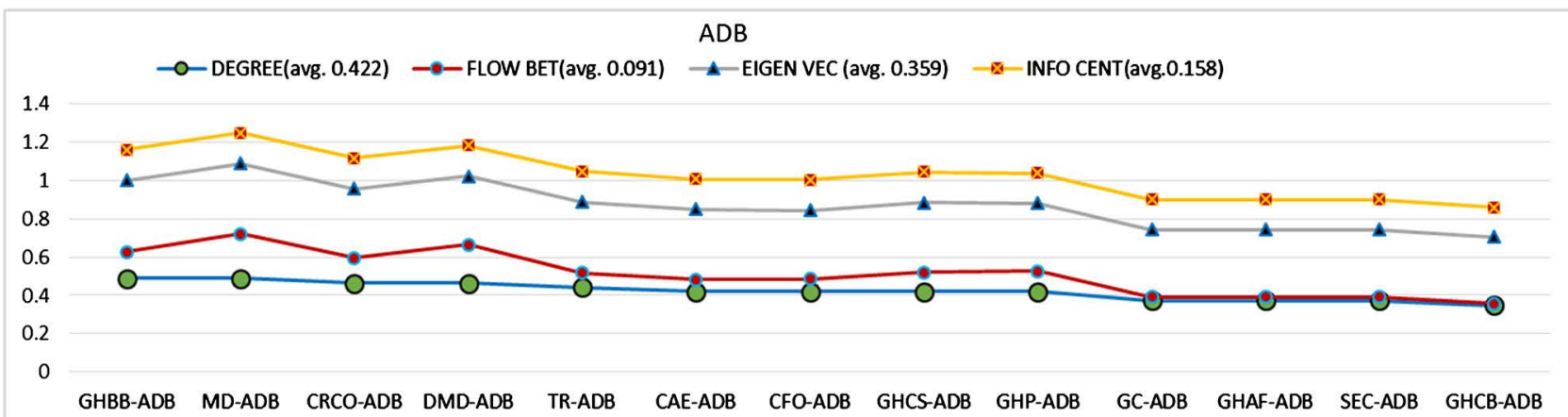

Figure 8. Agricultural development bank ego net.

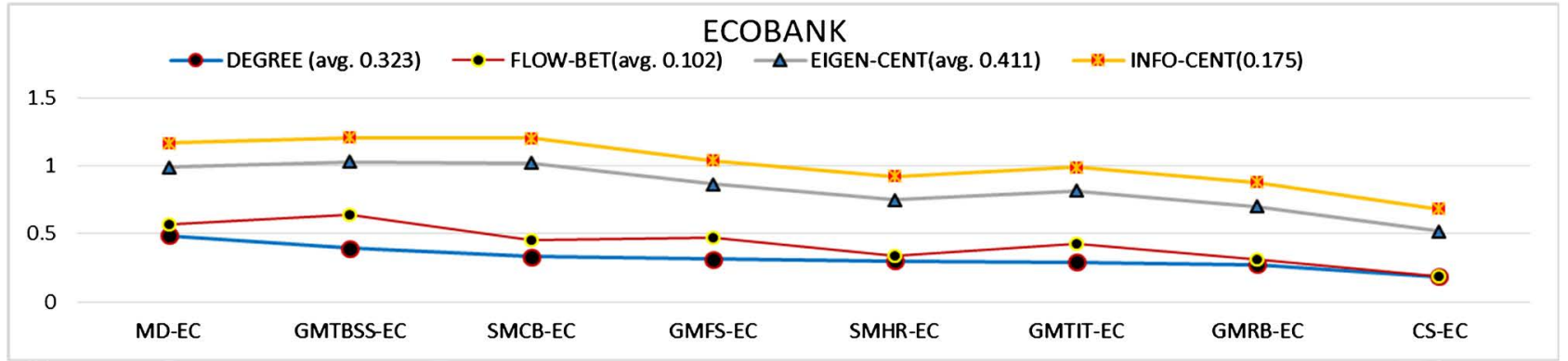

Figure 9. EcoBank ego net.

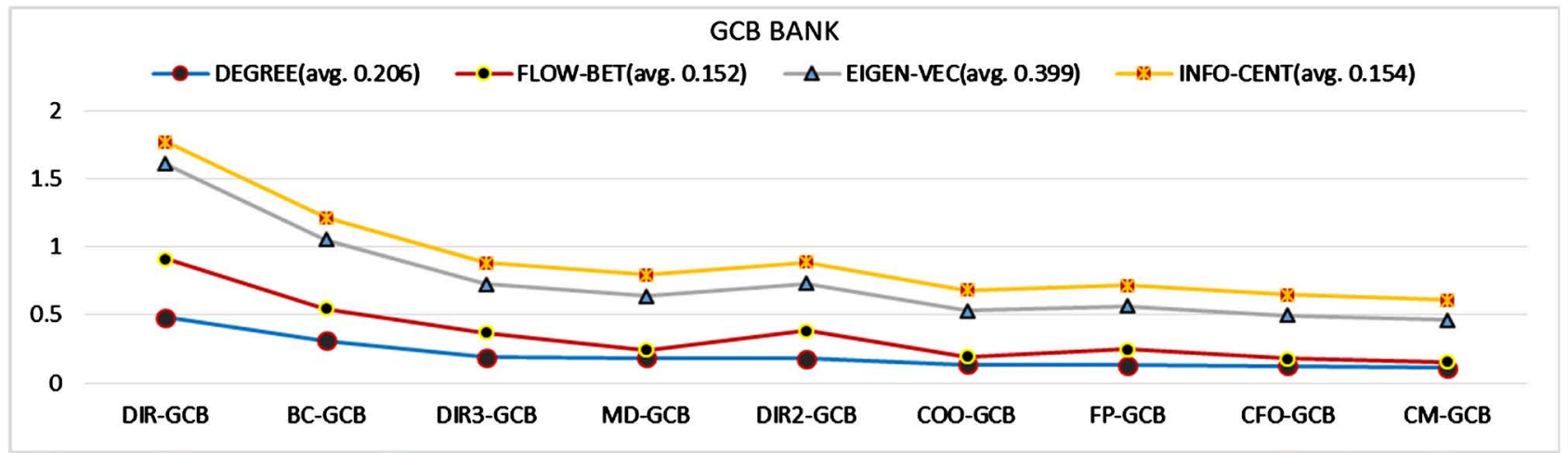

Figure 10. GCB Bank ego net. 


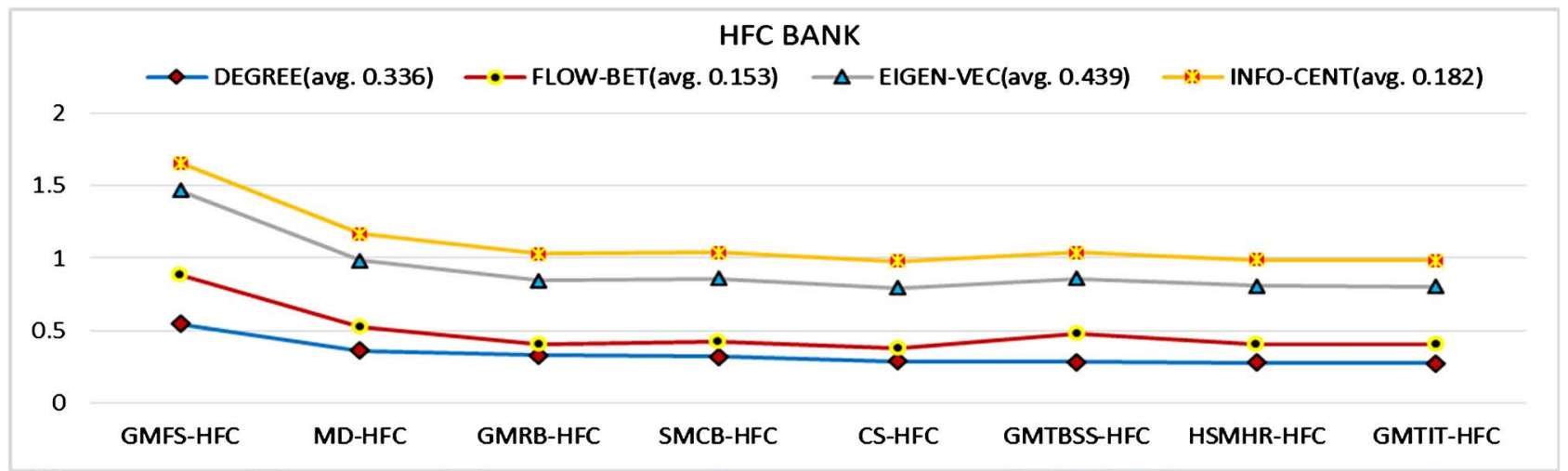

Figure 11. HFC bank ego net.

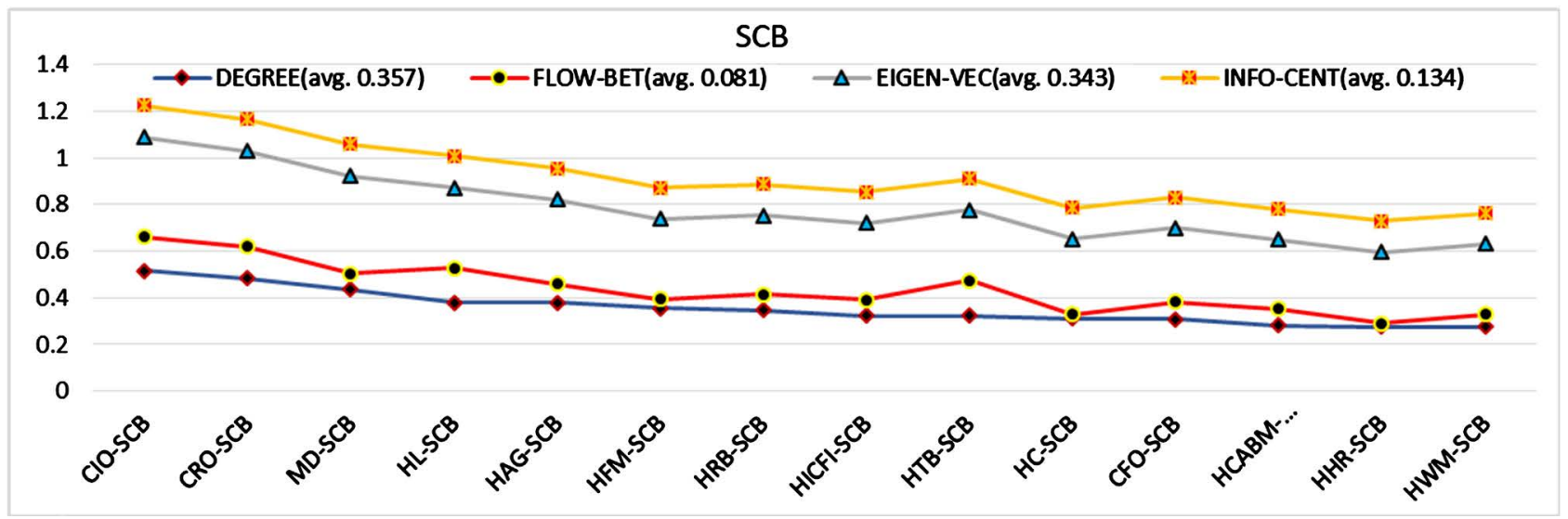

Figure 12. SCB ego net.

Figure 11 represents the Egonet of access Bank capturing its average degree centrality (0.336) and information centrality of 0.182 .

Figure 12 represents the Egonet of access Bank capturing its average degree centrality (0.375) and information centrality of 0.134 .

\section{Discussions and Conclusions}

The centrality of the Management team in human capital development is an agelong concept that has evolved from their major role in advancing the knowledge and skills required by an institution. The variability of the possession of the needed human capital and the ability of actors to transfer knowledge in institutional networks is of major concern in modern times for competitiveness and institutional performance. Bantel and Jackson [64] in a study of the composition of the management team and innovation adoption established that Management is the most dominant corporate governance structure that influence major decision-making in an institution and thus the ability to innovate and train staffs to adopt an innovation is pivoted on management team members, [43] [64] [65]. The discussions are done concerning the research questions hypothesized.

1) Do Multi-national banks have a stronger impact on human capital development of the financial sector network in emerging economies? 
Hierarchical clustering was used to answer research question 1 . The study revealed Multinational Banks dominated the highest hierarchy with 10 of its management appearing in the top hierarchy which was totaling 14 management team members. This emphasizes that the contribution of multi-national banks influencing the human capital development of host nations is well established in the literature [35] [66]. Multi-National industries control a huge base of human capital that is acquired through its strategic location in other bigger networks rather than the local network it participates in. This might also be hinged on Multi-national banks providing better conditions of services, therefore, attracting high-level management through poaching from the indigenous banks as the quality of human resources gives a competitive advantage to industries [1] [7] [67]. The first research question was therefore accepted based on the results derived.

2) Do the connection dynamics of actors in a financial network influence human capital development in emerging economies?

The second hypothesized research question of the study assessed connectivity types (qualitative; Eigen Vector Centrality versus quantitative; Degree Centrality connections) of management team members in the financial Network and its influences on the human capital development in emerging economies. The study established one's degree of connectivity, thus the total number of connections that a management team members have is essential in human capital development capacity. However, the quality of the connectivity (Eigen Vector centrality) of a node influences human capital development as compared to the quantity. Thus, the quality of the source of information is as critical to the development of the acceptance host as receiving information from a knowledgeable source that adds more to one's knowledge and vice versa. Research question two was therefore accepted on the grounds of the findings of the study.

3) Does management team members' positions held in a financial network influence their human capital development capacity in emerging economies?

The Third hypothesized research question assessed the position held in the financial network and its effect on human capital development in a highly competitive industry. It came to light from the results that actors' position held did not have a direct influence on human capital development but rather the actors' connection strength. Thus connection strength of actors in a highly competitive industry influences the human capital development capacity of the actors [16] [38] [68]. This indicates that there is no correlation, between position held and human capital development importance. Based on this finding, the study rejected the hypothesized research question 3.

\section{Recommendation for Future Studies}

We recommend future studies to ascertain the transformational capacities of banks in human capital development. Secondly, our future studies will assess the 
implication of the dynamics of human capital development on human resource policies and practices are fertile research grounds based on the findings of this study. Again we will explore the randomness of connection in social networks and its implication for human capital development.

Finally, our future studies will explore the sustainability of human capital within the network in the short and long run.

\section{Conflicts of Interest}

The authors declare no conflicts of interest regarding the publication of this paper.

\section{References}

[1] Alic, B. (2015) Investment in Human Capital-Prerequisite for the Growth of the Organizational Performance. Annals-Economy Series, Constantin Brancusi University, Faculty of Economics, 6, 65-73.

[2] Yukiko, M. (2016) Linking Knowledge Absorption and Transmission toward Innovation in R\&D Organizations. Proceedings of the European Conference on Knowledge Management, Coleraine, 2016, 667-675.

[3] Jeong, I. and Shin, S.J. (2019) High-Performance Work Practices and Organizational Creativity during Organizational Change: A Collective Learning Perspective. Journal of Management, 45, 909-925. https://doi.org/10.1177/0149206316685156

[4] Bechtel, R. (2007) Calculating Human Capital: The Market Based Valuation of the Human Resource. Zeitschrift für Personalforschung, 21, 206-231. https://doi.org/10.1177/239700220702100302

[5] Colbert, B.A. (2004) The Complex Resource-Based View: Implications for Theory and Practice in Strategic Human Resource Management. Academy of Management Review, 29, 341-358. https://doi.org/10.5465/amr.2004.13670987

[6] Wright, P.M. and Snell, S.A. (1991) Toward an Integrative View of Strategic Human Resource Management. Human Resource Management Review, 1, 203.

https://doi.org/10.1016/1053-4822(91)90015-5

[7] Delery, J.E. and Roumpi, D. (2017) Strategic Human Resource Management, Human Capital and Competitive Advantage: Is the Field Going in Circles? Human Resource Management Journal, 27, 1-21. https://doi.org/10.1111/1748-8583.12137

[8] Mitsakis, F.V. (2017) Employees' Perspectives on Strategic Human Resource Development before and after the Global Financial Crisis: Evidence from the Greek Banking Sector. International Journal of Training \& Development, 21, 285-303. https://doi.org/10.1111/ijtd.12112

[9] Wellman, B. (1983) Network Analysis: Some Basic Principles. Sociological Theory, 1, 155-200. https://doi.org/10.2307/202050

[10] Courgeau, D. (2016) Multilevel Network Analysis for the Social Sciences: Theory, Methods and Applications. Population, 71, 360-362. https://doi.org/10.3917/popu.1602.0381

[11] De Andrade, R.L. and Rêgo, L.C. (2018) The Use of Nodes Attributes in Social Network Analysis with an Application to an International Trade Network. Physica $A, 491,249-270$. https://doi.org/10.1016/j.physa.2017.08.126

[12] Barabási, A.-L., Ravasz, E. and Oltvai, Z. (2003) Hierarchical Organization of Modularity in Complex Networks. In: Pastor-Satorras, R., Rubi, M. and Diaz-Guilera, 
A., Eds., Statistical Mechanics of Complex Networks, Springer, Berlin, Heidelberg, 46-65. https://doi.org/10.1007/978-3-540-44943-0_4

[13] Kemper, A. (2010) Complex Networks Theory. In: Valuation of Network Effects in Software Markets. A Complex Networks Approach, Physica-Verlag HD, Heidelberg, 135-157. https://doi.org/10.1007/978-3-7908-2367-7_10

[14] Ren, G., et al. (2019) Analyzing the Topological Characteristic and Key Nodes of Chinese Air Sector Network. International Journal of Modern Physics B, 33, Article ID: 1950100. https://doi.org/10.1142/S0217979219501005

[15] Sih, A., Hanser, S.F. and McHugh, K.A. (2009) Social Network Theory: New Insights and Issues for Behavioral Ecologists. Behavioral Ecology and Sociobiology, 63, 975-988. https://doi.org/10.1007/s00265-009-0725-6

[16] Zamzami, N. and Schiffauerova, A. (2017) The Impact of Individual Collaborative Activities on Knowledge Creation and Transmission. Scientometrics, 111, 1385-1413. https://doi.org/10.1007/s11192-017-2350-x

[17] Chen, L., et al. (2018) Cycle Index of Uncertain Random Graph. Journal of Intelligent \& Fuzzy Systems, 34, 4249-4259. https://doi.org/10.3233/JIFS-17373

[18] Das, K., et al. (2020) Influential Nodes in Social Networks: Centrality Measures. In: Handbook of Research on Advanced Applications of Graph Theory in Modern Society, IGI Global, Hershey, 371-385. https://doi.org/10.4018/978-1-5225-9380-5.ch015

[19] Froehlich, D.E., Rehm, M. and Rienties, B.C. (2020) Mixed Methods Approaches to Social Network Analysis. Routledge, London. https://doi.org/10.4324/9780429056826

[20] Yousefi Nooraie, R., et al. (2020) Social Network Analysis: An Example of Fusion between Quantitative and Qualitative Methods. Journal of Mixed Methods Research, 14, 110-124.

[21] Zedan, S. and Miller, W. (2017) Using Social Network Analysis to Identify Stakeholders' Influence on Energy Efficiency of Housing. International Journal of Engineering Business Management, 9. https://doi.org/10.1177/1847979017712629

[22] Dubitzky, W., et al. (2013) Network Measures. In: Dubitzky, W., et al., Eds., Encyclopedia of Systems Biology, Springer, New York, 1515. https://doi.org/10.1007/978-1-4419-9863-7_101014

[23] Yap, H.Y. and Lim, T.-M. (2017) Social Trust: Impacts on Social Influential Diffusion. International Journal of Web Information Systems, 13, 199-219. https://doi.org/10.1108/IJWIS-11-2016-0067

[24] Akpinar, T. and Gün, S. (2016) Testing the Human Capital Development Model: The Case of Apprenticeships in Turkey. International Journal of Training and Development, 20, 214-223. https://doi.org/10.1111/ijtd.12084

[25] Alhajj, R. and Rokne, J. (2014) Actor-Network Theory. In: Alhajj, R. and Rokne, J., Eds., Encyclopedia of Social Network Analysis and Mining, Springer, New York, 18. https://doi.org/10.1007/978-1-4614-6170-8_110143

[26] Zendejas, G. and Chiasson, M. (2008) Reassembling the Information Technology Innovation Process: An Actor Network Theory Method for Managing the Initiation, Production, and Diffusion of Innovations. Springer US, Boston. https://doi.org/10.1007/978-0-387-87503-3_30

[27] Norbutas, L. and Corten, R. (2018) Network Structure and Economic Prosperity in Municipalities: A Large-Scale Test of Social Capital Theory Using Social Media Data. Social Networks, 52, 120-134. https://doi.org/10.1016/j.socnet.2017.06.002 
[28] Latora, V. and Marchiori, M. (2001) Efficient Behavior of Small-World Networks. Physical Review Letters, 87, Article ID: 198701. https://doi.org/10.1103/PhysRevLett.87.198701

[29] Barnes, M., et al. (2016) When Is Brokerage Negatively Associated with Economic Benefits? Ethnic Diversity, Competition, and Common-Pool Resources. Social Networks, 45, 55-65. https://doi.org/10.1016/j.socnet.2015.11.004

[30] Chahin, A., et al. (2017) Prerequisites for the Modelling and Analysis of a Product Development Process Using Network Theory. Springer International Publishing, Cham. https://doi.org/10.1007/978-3-319-49103-5_20

[31] Watts, D.J. and Strogatz, S.H. (1998) Collective Dynamics of "Small-World" Networks. Nature, 393, 440. https://doi.org/10.1038/30918

[32] Borgatti, S.P. and Halgin, D.S. (2011) On Network Theory. Organization Science, 22, 1168-1181. https://doi.org/10.1287/orsc.1100.0641

[33] Freeman, L.C. (1977) A Set of Measures of Centrality Based on Betweenness. Sociometry, 40, 35-41. https://doi.org/10.2307/3033543

[34] Alhajj, R. and Rokne, J. (2018) Social Network Analysis. In: Alhajj, R. and Rokne, J., Eds., Encyclopedia of Social Network Analysis and Mining, Springer, New York, 2665. https://doi.org/10.1007/978-1-4939-7131-2_101152

[35] Andersson, U., Forsgren, M. and Holm, U. (2002) The Strategic Impact of External Networks: Subsidiary Performance and Competence Development in the Multinational Corporation. Strategic Management Journal, 23, 979-996. https://doi.org/10.1002/smj.267

[36] Carol, W. (2008) Measuring Social Capital and Knowledge Networks. Journal of Knowledge Management, 12, 65-78. https://doi.org/10.1108/13673270810902948

[37] Isabelle, N. and Sylvie, F. (2015) Business Models and the Diffusion of Eco-Innovations in the Eco-Mobility Sector. Society and Business Review, 10, 203-222. https://doi.org/10.1108/SBR-07-2015-0024

[38] Tsai, W. (2001) Knowledge Transfer in Intraorganizational Networks: Effects of Network Position and Absorptive Capacity on Business Unit Innovation and Performance. Academy of Management Journal, 44, 996-1004. https://doi.org/10.2307/3069443

[39] Cellerino, A. and Sanguanini, M. (2018) Network Analysis. In: Cellerino, A. and Sanguanini, M., Eds., Transcriptome Analysis. Introduction and Examples from the Neurosciences, Scuola Normale Superiore, Pisa, 99-119. https://doi.org/10.1007/978-88-7642-642-1_7

[40] Borgatti, S.P. (2005) Centrality and Network Flow. Social Networks, 27, 55-71. https://doi.org/10.1016/j.socnet.2004.11.008

[41] Kimberl, M. (2018) Understanding the Value of Networking for Job and Career Development.

https://www.td.org/insights/understanding-the-value-of-networking-for-job-and-ca reer-development

[42] Tumelero, C., et al. (2018) The Role of Networks in Technological Capability: A Technology-Based Companies Perspective. Journal of Global Entrepreneurship Research, 8, 7. https://doi.org/10.1186/s40497-018-0095-5

[43] Bantel, K.A. (1993) Strategic Clarity in Banking: Role of Top Management-Team Demography. Psychological Reports, 73, 1187-1201. https://doi.org/10.2466/pr0.1993.73.3f.1187

[44] Kong, Y.S., Dankyi, A.B., Ankomah-Asare, E.T. and Addo, A.A. (2019) An Applica- 
tion of TOPSIS Approach in Determination of Spread Influencers in a Competitive Industrial Space: Evidence from the Banking Network of Ghana. Journal of Human Resource and Sustainability Studies, 7, 16. https://doi.org/10.4236/jhrss.2019.72020

[45] Flaig, M., et al. (2018) Conceptual Change and Knowledge Integration as Learning Processes in Higher Education: A Latent Transition Analysis. Learning \& Individual Differences, 62, 49-61. https://doi.org/10.1016/j.lindif.2017.12.008

[46] Le Heron, R. (1995) Editorial: Territorial Knowledges: Part of Being an Educated Person in the Future. Journal of Geography in Higher Education, 19, 125-127. https://doi.org/10.1080/03098269508709296

[47] Ryan, M. and Carmichael, M.-A. (2016) Shaping (Reflexive) Professional Identities across an Undergraduate Degree Programme: A Longitudinal Case Study. Teaching in Higher Education, 21, 151-165. https://doi.org/10.1080/13562517.2015.1122586

[48] Hussinger, K. (2012) Absorptive Capacity and Post-Acquisition Inventor Productivity. The Journal of Technology Transfer, 37, 490-507. https://doi.org/10.1007/s10961-010-9199-y

[49] Hager, M. and Seibt, T. (2017) Coping Patterns as a Starting Point for Individual Job Design. Proceedings of the Multidisciplinary Academic Conference, Prague, 2017, 169-184.

[50] Jackson, D. and Wilton, N. (2017) Perceived Employability among Undergraduates and the Importance of Career Self-Management, Work Experience and Individual Characteristics. Higher Education Research and Development, 36, 747-762. https://doi.org/10.1080/07294360.2016.1229270

[51] Heckert, T.M., et al. (2002) Effect of Gender and Work Experience on Importance of Job Characteristics When Considering Job Offers. College Student Journal, 36, 344.

[52] Prandy, K. (1965) Professional Organization in Great Britain. Industrial Relations, 5, 67-79. https://doi.org/10.1111/j.1468-232X.1965.tb00440.x

[53] Farrell, B. and Cobbin, D. (2000) An Analysis of the Ethical Environment of the International Accounting Profession. Business Ethics. A European Review, 9, 20-30. https://doi.org/10.1111/1467-8608.00166

[54] Khan, M.S. (2016) Maximizing the Finance Skill Set (Cover Story). Human Capital, $20,22$.

[55] Harvey, C.H. (2014) The Importance of Being Credentialed. Journal of Environmental Health, 77, 6-7.

[56] Graham, J.R. and Shier, M.L. (2014) Profession and Workplace Expectations of Social Workers: Implications for Social Worker Subjective Well-Being. Journal of Social Work Practice, 28, 95-110. https://doi.org/10.1080/02650533.2013.810613

[57] Lash, A.A. (1986) Theoretical Functions of Professional Associations. Turk Hemsireler Dergisi, 36, 9-14.

[58] Merton, R.K. (1969) The Functions of the Professional Association. American Journal of Hospital Pharmacy, 26, 636-641. https://doi.org/10.1093/ajhp/26.11.636

[59] Ivanova, E., Maier, M.J. and Meyer, M. (2015) Professional and Business Associations in Russia: Functions and Their Determinants. Academy of Management Annual Meeting Proceedings, 2015, 13173. https://doi.org/10.5465/ambpp.2015.13173abstract

[60] Thompson, G. (2016) The American Association for Agricultural Education: Our Powerful Professional Organization Made Up of Remarkable Faculty Members. Journal of Agricultural Education, 57, 1-11. https://doi.org/10.5032/jae.2016.01001 
[61] Jawor-Joniewicz, A. and Sienkiewicz, Ł. (2016) Human Capital and HRM as a Source of Competitive Advantage and Effectiveness: Evidence from Poland. In: Trąpczyński, P., Puślecki, Ł. and Jarosiński, M., Eds., Competitiveness of CEE Economies and Businesses. Multidisciplinary Perspectives on Challenges and Opportunities, Springer International Publishing, Cham, 175-196. https://doi.org/10.1007/978-3-319-39654-5_9

[62] Merriman, K.K. (2017) Sustaining Human Capital Value. In: Valuation of Human Capital: Quantifying the Importance of an Assembled Workforce, Springer International Publishing, Cham, 69-76. https://doi.org/10.1007/978-3-319-58934-3_7

[63] Ravasz, E., et al. (2002) Hierarchical Organization of Modularity in Metabolic Networks. Science, 297, 1551-1555. https://doi.org/10.1126/science.1073374

[64] Bantel, K.A. and Jackson, S.E. (1989) Top Management and Innovations in Banking: Does the Composition of the Top Team Make a Difference? Strategic Management Journal, 10, 107-124. https://doi.org/10.1002/smj.4250100709

[65] Al Hattab, M. and Hamzeh, F. (2018) Simulating the Dynamics of Social Agents and Information Flows in BIM-Based Design. Automation in Construction, 92, 1-22. https://doi.org/10.1016/j.autcon.2018.03.024

[66] Kawai, N. (2015) Does Downsizing Really Matter? Evidence from Japanese Multinationals in the European Manufacturing Industry. The International Journal of Human Resource Management, 26, 501-519. https://doi.org/10.1080/09585192.2011.616525

[67] Alhajj, R. and Rokne, J. (2018) Human Capital. In: Alhajj, R. and Rokne, J., Eds., Encyclopedia of Social Network Analysis and Mining, Springer, New York, 1034-1034. https://doi.org/10.1007/978-1-4939-7131-2

[68] Laurien, K. and Jan, K. (2007) Diffusion of Innovations through Social Networks of Children. Young Consumers, 8, 36-51. https://doi.org/10.1108/17473610710733776 


\section{Appendix}

Table A1. Hierarchical clustering coefficient of individual actors.

\begin{tabular}{|c|c|c|c|}
\hline Actor & Clustering Coefficient & Actor & Clustering Coefficient \\
\hline BC-GCB & 0.126 & GMTBSS-HFC & 0.096 \\
\hline CFO-ADB & 0.096 & GMTIT-HFC & 0.061 \\
\hline CFO-EC & 0.072 & HAG-SCB & 0.095 \\
\hline CFO-GCB & 0.106 & HC-SCB & 0.106 \\
\hline CFO-SCB & 0.084 & HCABM-SCB & 0.106 \\
\hline CIO-SCB & 0.097 & HCC-AB & 0.081 \\
\hline CM-GCB & 0.098 & HFC-AB & 0.086 \\
\hline COO-EC & 0.08 & HFM-SCB & 0.108 \\
\hline COO-GCB & 0.084 & HHR-AB & 0.052 \\
\hline CRCO-ADB & 0.075 & HHR-SCB & 0.099 \\
\hline CRO-SCB & 0.077 & HICFI-SCB & 0.092 \\
\hline CS-HFC & 0.081 & HIT-AB & 0.077 \\
\hline DHRB-AB & 0.084 & HL-SCB & 0.096 \\
\hline DIR-GCB & 0.089 & HO-EC & 0.011 \\
\hline DIR2-GCB & 0.068 & HOIT-EC & 0.063 \\
\hline DIR3-GCB & 0.075 & HPS-AB & 0.062 \\
\hline DMD-ADB & 0.059 & HRB-SCB & 0.105 \\
\hline EDBD-AB & 0.08 & HSMHR-HFC & 0.083 \\
\hline EDCL-EC & 0.101 & HTB-SCB & 0.105 \\
\hline FP-GCB & 0.104 & HWM-SCB & 0.098 \\
\hline GC-ADB & 0.096 & INEC-EC & 0.066 \\
\hline GHAF-ADB & 0.134 & $\mathrm{MD}-\mathrm{AB}$ & 0.075 \\
\hline GHBB-ADB & 0.084 & $\mathrm{MD}-\mathrm{ADB}$ & 0.052 \\
\hline GHCB-AB & 0.065 & MD-EC & 0.1 \\
\hline GHCB-ADB & 0.091 & MD-GCB & 0.109 \\
\hline GHCS-ADB & 0.091 & MD-HFC & 0.053 \\
\hline GHP-ADB & 0.104 & MD-SCB & 0.039 \\
\hline GHPB-AB & 0.095 & NED-EC & 0.063 \\
\hline GHRB-AB & 0.073 & NEDR-EC & 0.083 \\
\hline GMFS-HFC & 0.078 & SEC-ADB & 0.105 \\
\hline GMRB-HFC & 0.136 & TR-ADB & 0.109 \\
\hline
\end{tabular}

